\title{
Fundamentación antropológica de la gestión directiva y de la empresa. Un intento de continuación del esquema de actos voluntarios dirigidos al fin de Tomás de Aquino, a partir de las observaciones realizadas por Leonardo Polo
}

\section{Anthropological Foundation of Business Governance and the Company. An Attempt to Continue Thomas Aquinas' Scheme of Voluntary Acts Directed to the End, Based on Observations Made by Leonardo Polo}

\author{
MARCO ANTONIO GARCÍA KIHN \\ Universidad del Istmo (Guatemala) \\ magarcia@unis.edu.gt \\ ORCID: 0000-0003-0286-7305
}

Resumen: La dirección o gobierno de la empresa es de vital importancia para su desarrollo y el de las personas que en ella trabajan y con quienes se relaciona. El estudio de la base antropológica de la acción puede aportar elementos importantes para la realización de dicha tarea. Para ello se propone un estudio de la propuesta acerca de los actos de la voluntad elaborado por Tomás de Aquino y a partir de los aportes de Leonardo Polo; se inicia con el estudio del afán posesivo y efusivo del hombre y se continúa con un análisis de la propuesta de Aquino a partir de las observaciones de Polo sobre este asunto. En las conclusiones se proponen los campos de aplicación a la gestión directiva y la empresa.

Palabras clave: Actos, Efusivo, Empresa, Leonardo Polo, Posesivo.

\begin{abstract}
The management or governance of the company is of vital importance for its development and that of the people who work in it and with whom it relates. The study of the anthropological basis of action can provide important elements for carrying out this task. To this end, a study of the proposal on the acts of the will elaborated by Thomas Aquinas and based on the contributions of Leonardo Polo is proposed; it begins with the study of human's possessive and effusive desire and continues with an analysis of Aquinas' proposal based on Polo's observations on this subject. In the conclusions, the fields of application to management and business are proposed.
\end{abstract}

Keywords: Acts, Effusive, Company, Leonardo Polo, Possessive. 


\section{PLANTEAMIENTO}

Se propone como base el estudio de los actos voluntarios dirigidos al fin del hombre para sugerir fundamentos en la gestión directiva dentro de la empresa porque "los comportamientos individuales dependen de una concepción del ser humano, se asuma o no que esto es así" el hombre es capaz de establecer sus propios fines, a diferencia de los animales cuyo actuar está determinado por los instintos y apetitos sensibles. Con ello, la actividad en estos seres se limita a la reacción de los impulsos de la vida sensitiva. En el caso del hombre, sus acciones se constituyen en un medio para alcanzar el fin buscado. Para ello, la persona dispondrá de la corporeidad, el entendimiento, la voluntad y los hábitos innatos; constituyendo las acciones en su manifestación. Una referencia en su actuar la encontrará en la influencia de su afán posesivo y el efusivo ${ }^{2}$.

Para lograr los fines debe realizar una disposición adecuada de los medios. Unos medios serán más altos que otros; asimismo un fin alcanzado se podrá convertir en medio para otro fin más alto. Esta cadena de medios y fines puede llegar a ser larga; es tarea humana ordenar los medios adecuadamente y reconocer su naturaleza medial respecto de los fines por alcanzar: el hombre siempre puede aspirar a más. La organización de los medios corre en buena medida a cargo de la razón práctica. Sin embargo, no basta para organizarlos adecuadamente. Esta debe ser acompañada por la virtud, que permite ordenar los medios en favor del hombre. Con la confluencia de la razón práctica y la virtud de la prudencia se favorecerá la ordenación adecuada de los medios y los fines; de esta forma también se propiciará que hombre quede constituido como fin y no como medio, al ordenar jerárquicamente respecto de lo superior. El hombre podrá establecer el perfeccionamiento y el servicio a otros como fin únicamente si confluyen en su actuar el afán efusivo y el posesivo ${ }^{3}$.

El planteamiento anterior constituye ya una superación del utilitarismo. Sin embargo, podría dar lugar a una interpretación necesaria de la actividad del hombre, pues la voluntad siempre busca el bien y, por lo tanto, sería una búsqueda necesaria y no libre. Para desactivar esta posible aporía, es conveniente recordar que, según la propuesta poliana, la libertad es radicalmente personal -de la persona- y no voluntaria. Ahora bien, el perfeccionamiento de la virtud acepta todavía una finalidad más alta: la destinación. La destinación

1 Gallego, J. A.; Fernández, F. y Gómez, R. (2019), p. 13.

2 Cfr. Polo, L. (2015f), pp. 233-234. Filosofía política, pro manuscripto, pp. 59-60.

3 Cfr. Polo, L. (2015a), pp. 431, 434-435. Filosofía política, pro manuscripto, p. 60. 
de cada uno es libre: el hombre es libre respecto de su fin. La libertad la ejerce en el establecimiento de los fines pero no en el modo de disponer sobre sus dimensiones humanas. La libertad personal debe encaminarse a su destinación y dispone de los hábitos innatos, en concreto de la sindéresis, para actuar en sus potencias esenciales y en su cuerpo. En esto radica la importancia de conocer los actos voluntarios dirigidos al fin, pues el hombre manifiesta a través de ellos su destinación ${ }^{4}$.

En este trabajo se estudiará la propuesta poliana acerca de los actos voluntarios dirigidos al fin. Esta fundamentación de la acción puede servir para iluminar el modo de trabajar y de constituir la empresa. Para ello, se atenderá inicialmente a lo dicho por Polo acerca de los afanes efusivo y posesivo en el hombre. Luego se presentarán sus comentarios acerca de la propuesta de Tomás de Aquino sobre los actos voluntarios dirigidos al fin. A continuación, se presentará la propuesta de continuación y rectificación a partir del afán posesivo y efusivo presentes en la persona siguiendo las observaciones realizadas por Polo. Por último, se tratará sobre la fruición, como un afecto personal generado a partir de la aceptación libre del origen y destinación personal. Es importante señalar que nunca fue nuestra intención hacer esta propuesta de rectificación, pero al estudiar lo dicho por Leonardo Polo sobre este tema, se torna necesario partir de una genuina búsqueda de la verdad.

\section{NOTAS SOBRE EL AFÁN POSESIVO Y EL EFUSIVO EN EL HOMBRE}

Para comprender la acción humana es importante abordar el estudio de los dos tipos de afán presentes en el obrar humano: el afán posesivo y el afán efusivo. Sobre el afán posesivo, lo primero que cabe señalar es que en el hombre se presenta en distintos niveles; según la dimensión de la naturaleza humana, esta capacidad pude ser ejercida por la dimensión corporal, la dimensión cognoscitiva o por la dimensión volitiva. En cuanto al afán posesivo referido a la dimensión corporal, este se enfoca en la posesión de bienes materiales, esto es posible pues el cuerpo es potencial. Si ya estuviera concluido, no le sería posible adscribirse bienes ${ }^{5}$.

Ya los griegos notaron que la capacidad de tener es una característica bu$m a n a^{6}$, la cual no es compartida por los animales. Al explicar la posesión ma-

\footnotetext{
Cfr. Polo, L. (2015c), p. 204; (2015b), p. 122.

Cfr. Polo, L. (2017), p. 80; Polo, L. (2011), p. 17.

Cfr. Polo, L., (2019), p. 166.
} 
terial, Polo utiliza el ejemplo propuesto por Aristóteles con relación a la tenencia de un vestido y su diferencia con los animales. Mientras el hombre es propietario del vestido, el animal al cual se le "vistiera" con un traje, no posee el traje, lo lleva encima. Sigue indicando que "es importante poner de manifiesto el tener, porque el hombre es un ser capaz de posesión; y lo es en tanto que es una naturaleza peculiar" En cambio, las posesiones cognitivas y volitivas son siempre convenientes y la capacidad de tenerlas puede crecer irrestrictamente, ya que el acto de ser personal actúa sobre la esencia, dotándole de su capacidad de crecimiento inagotable ${ }^{8}$.

Si el tener corpóreo puede ser ejercido correctamente, es importante reconocer la jerarquía existente entre los distintos tipos de posesión para lograrlo. De esta forma, el hombre podrá utilizar los teneres inferiores como medio para alcanzar los superiores: "no conviene detenerse en la capacidad posesiva" . Al hablar de los tipos y la jerarquía de los bienes, Polo -siguiendo a los griegos- indica que el nivel inferior es el nivel corpóreo-práctico; un segundo nivel serán las operaciones inmanentes; existe un tercer nivel que se refiere a la capacidad de la naturaleza humana de tener intrínsecamente una perfección, constituido por los hábitos adquiridos en la voluntad o virtudes voluntarias. Si hablamos de niveles, necesariamente nos referimos a jerarquías: es importante que los inferiores sirvan de medios para alcanzar los superiores y, de esta manera, pueda darse en el hombre la relación medio-fin. El hombre goza de la capacidad de descubrir medios en vista a los fines ${ }^{10}$.

En la actualidad, muchas veces se observan desórdenes en la jerarquía de la búsqueda de bienes, pues la obtención del resultado material se ha convertido en muchos casos en el criterio más importante, subordinando el tener cognoscitivo y dejando en entredicho el tener de los hábitos adquiridos. Para corregir esta situación es importante que el afán posesivo sea ejercitado en función del afán efusivo, lo cual se logra con la virtud de la templanza. Solo logrando este dominio, es posible abrirse al crecimiento de la esencia y a la búsqueda del bien común ${ }^{11}$.

7 Polo, L. (2018b), p. 213. Asimismo Cfr. pp. 273-275, 415-416. También Cfr. Polo, L. (2015e), pp. 3637.

8 García, J. (2011), p. 67.

9 Urabayen, J. (2003), p. 224.

10 Cfr. Polo, L. (2015d), p. 34

11 Cfr. Polo, L. (2015b), p. 416. Asimismo Cfr. Sellés, J. F. (2013), Nueve puntos centrales del directivo, pro manuscripto, p. 17. Está publicado en Familia, Universidad y Empresa, los tres agentes de cambio de la Sociedad. 
Polo es muy claro sobre el control que debe ejercerse sobre el afán posesivo, en cuanto a los beneficios económicos generados por la empresa y aboga por una distribución adecuada. Ya que "si se entiende que sólo es sujeto de beneficio una parte de la empresa, entonces ya estamos descontrolando, pues es difícil decir que se esté sirviendo a la sociedad. Al empresario que ve los salarios únicamente en el capítulo de gastos o de costos, hay que decirle que está dominado por el afán posesivo y, en consecuencia, que no sirve para gobernar"12.

Sellés, haciendo una referencia a los principales aspectos que Polo resaltaba sobre la manera de dirigir las empresas, señala que el dinero debe permitir convocar a otros para trabajar; en cuanto se le dé este sentido, se le dotará de un sentido ético, pues la fundación de una empresa requiere de fondos y este bien material lo permite. Esta capacidad convocatoria del dinero refleja la naturaleza medial del dinero y no de fin en sí mismo. "En este sentido, el dinero tiene sentido ético. En caso contrario, tiene exclusivamente un sentido pragmático. (...) El dinero tiene valor ético si empleándolo se consigue que el trabajo en potencia se mantenga y aumente. Es decir que la capacidad de convocatoria para trabajar sea cada vez mayor"'13. En ese mismo trabajo dice que otra manera de jerarquizar adecuadamente el afán posesivo en la empresa es considerar la contribución que la empresa realiza en la sociedad y el grado de contribución al desarrollo de las personas asociado a sus productos. En la medida en que permitan el desarrollo de las dimensiones más altas del hombre, cumplirán una función más bumanizante. Otro aspecto señalado por Polo sobre la manifestación del afán posesivo es la aspiración por ascender dentro de la empresa, subir de rango. Esto es bueno, pero si no se controla puede afectar al correcto actuar y a la colaboración interna de la empresa. De esta manera, el control que el afán efusivo ejerce es mediante la integración ${ }^{14}$.

Concluyamos diciendo que el afán posesivo debe ser valorado, aunque sea inferior al efusivo. Si no lo hiciéramos, caeríamos en una parcialidad antropológica peligrosa y falsa por no corresponder al modo de ser humano, pues el cuerpo tiene carácter posesivo ${ }^{15}$. Pero como el afán posesivo es tendencial y conveniente, nos lleva a buscar el beneficio en la actividad económica y al quedar templado por el afán efusivo la búsqueda del beneficio será

12 Polo, L. (2015b), p. 416.

13 Sellés, J. F., Nueve puntos centrales del directivo, pro manuscripto, p. 16.

14 Cfr. Polo, L. (2015c), pp. 153-156.

15 Cfr. Polo, L. (2015c), p. 156. 
compatible con el servicio a la sociedad. Los bienes materiales propician la capacidad de la búsqueda del mejoramiento de la esencia y un sano deseo de adscripción de bienes materiales, los cuales también constituyen fines buenos en sí mismos, aunque no suficientes para colmar la voluntad que es irrestricta. Si los bienes materiales fueran malos, implicarían que nuestra corporalidad también lo sería. También podemos señalar que la manera de usar los bienes materiales manifiesta de cierta manera quiénes somos ${ }^{16}$.

Ahora se presentarán algunas notas sobre el afán efusivo. Iniciemos diciendo que la persona es efusiva. Polo lo dice expresamente en repetidas ocasiones, es uno de los aportes más importantes y fundamentales de su antropología. Por eso es capaz de interactuar con otros en relaciones de suma positiva, es decir, donde el valor creado es positivo para ambas partes. También usa esta expresión cuando apunta que a diferencia de los animales puede aportar, sacar adelante proyectos a partir de su iniciativa: la libertad personal manifiesta su efusividad en las aportaciones realizadas ${ }^{17}$.

El hombre aporta porque la persona es efusiva: abre un ámbito en torno suyo en el que activamente se integra con los demás, no es un ser solitario sino dialógico: sólo puede ejercitar sus capacidades en plenitud con otras personas. Yepes aclara que al decir que una persona es dialógica, estamos refiriéndonos a su capacidad de dar. Si lo expresamos radicalmente, diremos que dar en el hombre es la capacidad de darse. Siguiendo este planteamiento, para darse es necesario que alguien acepte, pues no hay un dar en solitario. Dar y recibir son partes de una misma dualidad referida al amor, por lo que podríamos precisar que dicha dualidad es un darme amorosamente y un ser aceptado amorosamente. La relación entre el dar y el recibir nos refiere al don, a un don amo$\operatorname{ros} 0^{18}$.

La efusividad nace del amor. El amor es iniciativa y no un despertar ante lo deseable: "El amor lleva a descubrir el carácter 'personal' del hombre (...) El hombre es un ser innovante, de cuya actuación depende algo que, sin ella, no existe de ninguna manera. Es novante porque aporta; y no desde el mundo, sino desde sî” ${ }^{\prime 1}$. Esta capacidad de donación, permite traspasar la noción de la propiedad como requisito de la capacidad de donación: dona desde sí y no desde el tener. Por eso, la sentencia que dice que "nadie da lo que no tiene" es

16 Cfr. Polo, L. (2015b), p. 416.

17 Cfr. Polo, L. (2015b), pp. 381, 413. Asimismo en (2017), p. 233.

18 Cfr. Yepes, R. (1997), pp. 17-20 y p. 22.

19 Polo, L. (2015b), p. 248. 
correcta en cuanto a lo material, pero no en cuanto a lo personal, pues es capaz de crear $^{20}$.

La acción encuentra su origen en la intimidad personal, la cual no constituye una cerrazón en sí mismo sino relación de origen. El afán efusivo está llamado a regir sobre el afán posesivo, permitiendo de esta manera que el obrar se dirija a su origen: la persona humana. Polo indica que "una de las cosas más importantes para un empresario es saber armonizar la tendencia a la apropiación y la efusividad, porque sólo en tanto es efusivo es empresario. El placer es humano. El que quiere negarlo niega su condición humana. Pero por encima del placer está el agrado, y por encima el gozo"21. La capacidad de la persona de apreciar lo bello y lo valioso queda supeditada a su capacidad de controlar el afán posesivo desde el afán efusivo. Además, al manifestar la intimidad de la persona, si uno quiere conocerse podrá encontrar buenos indicios de quién es a partir de lo que aporta. Por así decirlo, hace posible intuir una faceta de su intimidad, pues en las acciones la persona deja su sello ${ }^{22}$.

La efusividad de la persona da origen al aspecto social de la persona. La persona no aporta porque está en sociedad, sino que al ser efusiva se abre a esta dimensión. Esto lo aclara al decir que "es un error entender al hombre como ser necesitante. La manifestación personal no es signo de indigencia, sino aportación positiva (...). Por eso trasciende, en el modo de manifestación, la individualidad. La sociedad no es ajena a la persona, sino su estricta dimensión efusiva"23.

El obrar humano tiene sentido en cuanto que sus frutos son compartidos entre quienes lo llevan a cabo y quienes reciben sus frutos, tanto directamente como aquellos otros que pertenecen al plexo social en que se realiza el actuar. Ese compartir manifiesta la sociabilidad humana. Ahora bien, si a la sociabilidad humana le incorporamos el don amoroso, éste amplía y eleva la sociabilidad humana al orden del amor personal, el fin se eleva al bien del otro por ser persona; este amor lleva a excederse de lo necesario y justo; la dignidad de quien lleva a cabo la acción es el único límite que obliga a que sea resguardada y favorecida. La grandeza del don radica en que, por ser una manifestación del amor personal, amplía y eleva la sociabilidad bumana ${ }^{24}$.

20 Cfr. Polo, L. (2015b), p. 413.

21 Polo, L. (2015b), p. 413.

22 Cfr. Ferrer, U. (2010), p. 113.

23 Polo, L. La sociedad, pro manuscripto, p. 2.

24 Cfr. Rodríguez Sedano, A. (2001), p. 26. Cfr. asimismo: Rodríguez Sedano, A. y Aguilera, J. C. (2011), p. 48. 
La persona podrá proponerse la efusividad en su obrar si es capaz de "querer querer más", como Polo definía el deseo de la persona por mejorar. Este modo de querer -el cual no se refiere a la satisfacción de los apetitos- permite a la persona incrementar su alteridad con los demás: le permite aumentar su sociabilidad, pues ya no sólo busca su bien, sino que se abre a la búsqueda activa del bien de los demás. Para poder actuar de esta manera, debe ser considerada mejor la donación que la apropiación de bienes por quien actúa ${ }^{25}$.

Para no paralizarse en algo medial, lo que pudiera ser un fin inicialmente conviene convertirlo en medio respecto de algo superior. No es conveniente para el hombre establecer como fin último lo que de suyo es un medio para el hombre. "Lo primario, lo más importante es el servicio (...) El servicio es la actitud efusiva, que tiene una gran influencia en el modo en que se busca y se aprecia el beneficio. No se deben hacer cosas que beneficien a la empresa, pero que son perjudiciales socialmente" 26 .

El dar siempre implica un don; ese don puede ser material o inmaterial. La materialidad queda incluida en cuanto que el hombre posee corporeidad y, por lo tanto, también manifiesta a través de sus bienes las disposiciones personales. De ahí la importancia de la adscripción de bienes materiales a partir del obrar humano. De esta manera, no se niega el afán posesivo, sino que se supedita al afán efusivo de la persona. Polo lo indica cuando dice que "es sumamente importante que el deseo no mate o deje sepultado el afán efusivo. Por eso hace falta la virtud, que pone el poseer en subordinación del apor$\operatorname{tar}^{227}$. En ese mismo texto explica la repercusión positiva que tiene el ejercicio del afán efusivo en la inventiva, el gobierno, el diálogo y la participación dentro de la empresa.

En el caso de la empresa, Polo indica que el "afán de crear, afán de inventar (...) es un afán efusivo. Si hay afán de crear, también hay afán de compartir. Por lo tanto, cuando se comparte también uno es templado. (...) Realmente lo que hay que compartir es el gozo, el diálogo, porque la alegría tiene que ver con la efusividad, pues busca la comunicación. Uno está suficientemente alegre no cuando está solo, sino cuando comunica su alegría. Uno no se alegra solo"28. La efusividad lleva a abrirse al otro, a considerarlo. No se puede crear solo para uno mismo, el crear-que es efusivo- remite al compartir y el

25 Cfr. Polo, L., La conexión de las virtudes, pro manuscripto, p. 29.

26 Polo, L. (2015b), p. 416.

27 Polo, L. (2015b), p. 413.

28 Polo, L. (2015b), p.416. 
compartir da lugar a la alegría. El anhelo de felicidad es algo reconocido por los griegos, quienes establecieron la felicidad como el fin de la ética.

Una vez establecida la confluencia en el hombre de dos afanes -que a primera vista podrían parecer contrapuestos pero que si se comprenden según la antropología humana se comprende que son complementarios-, se puede pasar a analizar la propuesta de Tomás de Aquino y las continuaciones y rectificaciones que se pueden proponer a partir de lo dicho por Polo.

\section{LOS ACTOS DE LA VOLUNTAD REFERIDOS AL FIN, SEGÚN LA PROPUESTA DE TOMÁS DE AQUINO}

Iniciamos el análisis de los actos voluntarios recordando que la voluntad es una potencia tendencial, es decir, tiende a un fin de una manera libre, no determinada. Para comprender la manera en que esto ocurre en el hombre, Polo se basa en la propuesta de Tomás de Aquino acerca de los actos voluntarios -la que considera como una gran contribución-. La voluntad se dirigirá a su fin mediante tres actos: el simple querer, la intención y la fruición. Cada uno de estos actos sucede al anterior, por lo que guardan una estrecha relación ${ }^{29}$.

Simple querer o simplex velle. El simple querer o simplex velle es un acto que se ejerce por el fin en sí mismo, al margen de que se posea o no; no apunta a ningún bien determinado, sino a cualquier bien por ser digno de ser querido: la voluntad manifiesta su verdad con el querer. Este querer no es convertido en acto por la inteligencia, sino por la activación de la voluntad desde la sindéresis. Por esta aportación de la sindéresis, la voluntad nativa es capaz de querer y establecer una relación trascendental con el bien. Ya la filosofía medieval reconocía que la voluntad es una potencia pasiva en estado de naturaleza -voluntas ut natura-, la voluntad tiende naturalmente al fin último felicitario ${ }^{30}$.

Polo también se refiere al primer acto como simple querer-yo, para remarcar la relación que guarda con la dimensión superior de la sindéresis: el querer-yo. El simple querer-yo es iluminado desde la sindéresis. A partir del simple querer son constituidos los demás actos voluntarios en la voluntad ya $\operatorname{activada}^{31}$.

29 Cfr. Polo, L. (2015a), p. 424, p. 428. Cfr. asimismo: La conexión de las virtudes, pro manuscripto, pp. 5-6.

30 Polo, L. (2015b), pp. 216, 410, 423. Asimismo Cfr. Sellés, J. F. (1999), p. 189.

31 Cfr. Polo, L. (2015b), pp. 410-411. 
Lo anterior también se puede explicar al decir que a partir del simple querer-yo la voluntad toma impulso, es capaz de desear y tender al bien. Polo indica que, por la naturaleza de potencia pasiva, la voluntad debe ser activada por el querer-yo para poder constituir sus actos y, por esa dependencia, la voluntad se relaciona con la sindéresis de forma más intensa que la inteligencia. La voluntad requiere de este hábito innato para constituir su primer acto y, a partir de este, sus demás actos. Otro aspecto importante de esta relación radica en que su querer no es necesario, sino libre y manifestativo de la persona. Esa manifestación en último término queda referida al amor personal. Por eso aclara que "son precisos los actos voluntarios, a través de los cuales, el bien es congruente con el amor" 32 .

La tendencia voluntaria no es estática, puede incrementarse y permitir querer más bien. Polo llama a esto querer-querer-más, es decir, un acto que incrementa y mejora el deseo voluntario por un bien más alto. El querer-querermás ocurre en cuanto la voluntad es iluminada con mayor intensidad por la sindéresis, que a su vez es iluminada desde la persona. Debido a que los actos de la voluntad son constituidos por la sindéresis, si se intensifica la relación entre ambas, la intención de otro será creciente. Por eso se caracteriza por el tender creciente referido a lo ausente y, por lo tanto, no puede ser referido a sí mismo pues el ser ya se posee ${ }^{33}$.

Polo indica que la intención es creciente según el desarrollo de esta potencia. Por eso, siempre es posible querer-más-otro. Esta capacidad de crecimiento irrestricto permite la referencia de la voluntad al bien trascendental a lo que Polo llama intentio finis-. Ahora bien, por no ser una tendencia necesaria, permite su contrario: no crecer o decrecer. En la actualidad en muchas ocasiones se concede demasiada atención a los medios; esto debilita la intención, pues deja de tener relación con el bien trascendental ${ }^{34}$.

Cuando el crecimiento del querer ocurre, confluyen el querer-querer-más y del querer-más-otro, con ello la voluntad se abre hacia el prójimo. Ya se mencionó que la voluntad es iluminada por el querer-yo de la sindéresis; asimismo, se indicó que esta dimensión de la sindéresis está relacionada con el amor personal; de ahí se puede decir que el querer al prójimo debe ser como el querer propio, el cual reclama aceptación, ser correspondido amorosamente. Sin esta posibilidad de correspondencia el orden moral carecería de validez ${ }^{35}$.

32 Polo, L. (2015b), p. 404. Cfr. asimismo: pp. 410, 439.

33 Cfr. Polo, L. (2015b), p. 467, pp. 492-493. Cfr. asimismo: Corazón, R. (2003), p. 218.

34 Cfr. Polo, L. (2015b), pp. 432-436. Cfr. asimismo: Polo, L., La conexión de las virtudes. pro manuscripto, 5.

35 Cfr. Polo, L. (2015b), pp. 492-493. 
La voluntad al ser una potencia no determinada puede crecer o bien actuar en contra de su verdad. En este último caso, la voluntad se destruye al negase a querer o queda debilitada al dejar de querer-más. Polo llama a esta última realidad obstinación. Esta es aquella disposición en la voluntad que impide al hombre mejorar el querer respecto de los fines; al paralizar el mejoramiento en el querer voluntario, ocurre una inversión en la relación de la sindéresis con la voluntad, ya que esta última pretende constituir a la sindéresis e impide la intención de otro. Además, se desvanece y se cierra en sí misma. La posibilidad de obstinarse es factible porque el querer es un deber libre, no está impuesto por un instinto. Ahora bien, tampoco es un querer autónomo ni espontáneo, sino un acuerdo esencial entre la interacción de la sindéresis y la voluntad, con el cual se constituye la verdad de la voluntad ${ }^{36}$.

El imperar de la sindéresis en la voluntad puede expresarse como: ¡quiere, haz el bien!, pues querer es tu verdad. La primera parte de este imperativo se cumple en el simple querer: ¡quiere! Sin embargo, el simple querer no opera, sino que abre la posibilidad de ser continuado con los otros actos de la voluntad y alcanzar con ellos el segundo tramo de este deber: ¡haz el bien! Esto es posible debido a que en el simple querer se constituyen y afincan los demás actos de la voluntad. El bien querido en el primer acto voluntario puede ser intensificado con los otros actos voluntarios, quedando el primero como una labor de vigilancia sobre los demás actos sucesivos. El tercer tramo -querer es tu verdad- se constituye en cada uno de los actos voluntarios ${ }^{37}$.

Intención. Sigamos ahora con el segundo acto de la voluntad en cuanto referida al fin: la intención o intentio. Este acto es la referencia de la voluntad hacia el fin en tanto que ausente, constituye la búsqueda del bien ausente. La voluntad sigue tendiendo al bien mediante la intención y constituye el motivo para actuar. Debido a que la actuación se realiza dentro de un contexto determinado, este acto se inserta en un plexo. Por eso es necesario señalar que la intención se realiza a partir de los medios disponibles y de otros fines inferiores que fueron alcanzados previamente. Para lograr articular la intención es necesario organizar los medios a partir de la razón práctica. Por eso, la intención es posibilitada por el simple querer en cuanto al fin y por el acto intelectual del consejo en cuanto a los medios. La organización de los medios que forman el plexo es condición de posibilidad de la intención que tiende al fin ${ }^{38}$.

36 Cfr. Polo, L. (2015b), p. 423. Cfr. también: pp. 410-411 y 423-426.

37 Cfr. Polo, L. (2015b), pp. 410-411 y p. 433.

38 Cfr. Polo, L. (2015b), p. 402. Cfr. asimismo: Polo, L. La conexión de las virtudes, pro manuscripto, p. 5. 
En el caso de la voluntad, por ser una potencia que tiende a lo que no posee, una vez logrado un fin, éste se convierte en medio para otro superior. De ahí, que la intención siempre es posible y se refiere a otro fin distinto a quien quiere. La intención de otro -como llama Polo a la realidad de la voluntad intencionada a algo distinto del yo- se dirige a lo que la inteligencia le presenta mediante la razón práctica. Es decir, la voluntad quiere aquello que le presenta la razón práctica: no excluye otros bienes, sino que elige el que le es presentado: es electiva porque se dirige a unos bienes, pero no es sacrificial -es decir, que seleccione por desprecio de los otros bienes ofrecidos a ella, sino que prefiere un bien a otros. La voluntad es intencional según que cuenta con el conocer, no puede dirigirse a lo que no se conoce o a lo que no es real ${ }^{39}$.

Una de las diferencias más importantes entre el simple querer y la intención radica en el reconocimiento de los medios necesarios, ya que para hacer posible el bien buscado se debe conceder la importancia debida a los medios. Por eso Polo señala que "la intentio no se afronta con corrección si no se considera el juego de los medios en la vida humana" ${ }^{40}$. La disponibilidad de medios provoca variaciones en los fines buscados: no existe uniformidad. Sin embargo, no es esta la única causa de la multitud de fines distintos ni la más profunda. La libertad personal manifestada a través de la voluntad es la causa más profunda de dicha distinción. Esta es la causa que el querer no sea necesario, aunque su referencia al bien sea tendencial. Por eso Polo señala que la libertad esencial desciende o se sigue de la libertad personal ${ }^{41}$.

También se puede señalar que la intención tiene un doble sentido: por una parte, establece una relación entre los medios entre sí y, por otra, establece la relación de los medios con el fin. Esta dualidad de sentido de la intención - plexo y fin- provoca que para el hombre siempre le favorezca actuar en sociedad o dentro de un mercado y no de forma aislada. Al formar parte de una comunidad, puede establecer de mejor manera el ordenamiento de los medios y mejorar el ordenamiento de los medios desde la intención ${ }^{42}$.

En algunas ocasiones los medios tienen un marcado carácter de fin y esto puede llevar a confundirlo con un fin. Esta confusión es posible, ya que los medios, al formar parte de un plexo, pueden ser el objeto de una acción sin estar referidos a una intención o fin más elevado. Polo indica que por eso es

39 Cfr. Polo, L. (2015b), pp. 412-416.

40 Polo, L. (2015b), p. 433.

41 Cfr. Polo, L. (2017), p. 14

42 Cfr. Polo, L. (2015b), pp. 433 y 435. 
necesario distinguir entre los fines internos al plexo -a los que llama fines horizontales o inmediatos- $\mathrm{y}$ aquellos referidos a la intención del fin. Esta situación es especialmente delicada cuando se refiere a la tecnología, pues en muchos casos el progreso técnico induce a olvidar los fines más altos y se corre el riesgo de que los medios dominen la vida social, imponiéndose como si fueran fines automáticos. Para evitar este riesgo es necesario reconducir la eficacia a la verdad ${ }^{43}$.

Polo se refiere a otro aspecto de la intención y su carácter manifestativo en la acción, al cual se refiere como atravesar la obra. Para explicar este concepto, utiliza el ejemplo de una carta escrita: la acción de escribir continúa en el lector a través de lo que causa en él lo escrito. Por eso, también indica que la acción no concluye con la obra en sí misma, sino que en las buenas obras se continúa de acuerdo con la intentio finis. Esto también explica la razón por la que las obras malas carecen de esa prolongación en la intentio finis ${ }^{44}$. Las obras malas no están vinculadas a la intentio finis y, por lo tanto, al realizarlas el acto voluntario no se fortalece sino decrece. Polo explica que esto ocurre cuando se confunde el disponer esencial con lo disponible. Es decir, en vez de disponer de las facultades esenciales y motoras y los medios en orden a un fin superior, se dispone de las facultades esenciales, motoras y medios en orden a algo que por su naturaleza debiera ser un medio y no un fin ${ }^{45}$.

También cabe indicar que la intentio finis no sería posible según una interpretación culturalista de la acción, según la cual el actuar de la voluntad del hombre obedece a una instancia determinante o decisiva en la que está situada. Si así fuera el caso, el hombre se limitaría a asumir la cultura al momento de actuar: el actuar del hombre quedará modelado por la cultura y no por la libertad. Otro error sobre la acción lo constituye la visión vitalista. Esta concepción de la acción es todavía más contraria a la libertad; según esta el hombre actúa como llevado por la vida, sumirse en un ciclo que anticipa la acción y marca su sentido. Bajo esta visión predomina la sensualidad y el desconocimiento del espíritu humano y su afectividad ${ }^{46}$.

Se ha dicho que la voluntad se mueve a partir de la intención, es decir, ordena los medios disponibles a un fin y que la consecución de un fin medial abre la posibilidad a fines más altos. "Pero es claro que los fines que están más

43 Cfr. Polo, L. (2015b), p. 445.

44 Cfr. Polo, L. (2015b), pp. 449-450, p. 452 y p. 468.

45 Cfr. Polo, L. (2015b), p. 450.

46 Cfr. Polo, L. (2015b), pp. 412-416 y pp. 450-453. 
allá de los medios son, ante todo, los seres humanos" ${ }^{47}$. De ahí podemos concluir que, si los fines más altos se refieren a otras personas, "la intención del bien, propia de la voluntad, no es suficiente para la persona, sino que ha de estar respaldada por el amor"48. Esta relación existente entre la voluntad y el amor personal -trascendental personal más alto descubierto por Polo en su antropología- se establece mediante la sindéresis; más concretamente por el querer-yo.

Fruición. Siguiendo con la presentación de la propuesta de Tomás de Aquino, completemos el análisis de los actos de la voluntad referidos al fin con la fruición o fruitio. Este es el acto último y superior de la voluntad. Este acto corresponde al disfrute del fin en tanto que está presente -ya no se busca, pues es poseído- y se goza de él. También se le denomina a este acto delectación, quietud o gozo. La voluntad al poseer el bien mediante la fruición ya no tiende, sino que se descansa en la posesión del fin: se disfruta del bien -el tender se transforma en disfrutar del fin-. Por eso, la intención y la fruición no pueden darse juntas ${ }^{49}$.

Siguiendo con la propuesta clásica, también diremos que el fin de la voluntad es la felicidad; es decir, la voluntad tiende a la felicidad, alcanzando su grado sumo en la posesión del fin. Ahora bien, según esta propuesta, la captación de los bienes se inicia con el conocimiento de este, si se quedara corta en la captación de bienes cabe la posibilidad de equivocar un bien medial al considerarlo como el fin último. Por esta razón, la fruición no está garantizada y puede llegar a descansar en bienes que de suyo no son suficientes ${ }^{50}$.

Polo reconoce como válidos muchos aspectos planteados por Tomás de Aquino sobre la fruición. Por ejemplo, la posibilidad de intentar que descanse la fruición en un bien medial o en bienes aparentes por la incapacidad del intelecto de conocer el bien o por la posibilidad de error. También coinciden en que la fruición completa no es posible en este mundo, pues la posesión del bien trascendental ocurre después de la muerte. Así se explica el hecho que no es experimentable en forma plena: que no se agote la tendencia de la voluntad y la falta de una distinción absoluta entre la intención y la fruición.

Sin embargo, Polo señala algunos aspectos que considera que deben rectificarse en la propuesta clásica; se señalarán los dos aspectos que considera

47 Polo, L. (2015b), pp. 367, 450.

48 Polo, L. (2015a), p. 213.

49 Cfr. Polo, L. (2015b), pp. 76-77, pp. 424-426, p. 453.

50 Cfr. Polo, L. (2015b), pp. 424-426. 
más importantes. El primero de ellos es el contenido y la índole sobre lo que versa la fruición. Si la aprehensión del bien es de carácter intelectual, la fruición sería un acto de la voluntad en orden al intelecto. Según la propuesta poliana, es a la sindéresis -y no al intelecto- a la que le corresponde proporcionar lo que contempla la fruición. Precisando aún más, como la sindéresis manifiesta a la persona, la sindéresis es disponible a la persona según su conformación, es decir, según los trascendentales personales. Debido a ello, la sindéresis es de carácter co-existencial y a partir de esta característica también está referida a la felicidad de todos. Esta realidad constituye la base de la sociabilidad humana y la proyección de las obras en la búsqueda del bien común. Pero esta apertura no tiene carácter posesivo sino efusivo, en eso se separa de la propuesta de Aquino ${ }^{51}$.

El segundo aspecto por señalar será la apertura de la fruición a la felicidad de todos, pues este acto deberá ser susceptible de ser ofrecido a otros. Esta apertura nos remite a la relación de quien actúa con otros: debido a que la fruición ocurre al contemplar la felicidad de todos, la índole de la fruición está relacionada con el amor y no solo con la posesión del bien. Este aspecto lo indica claramente cuando dice que "entender la fruitio como último acto de la voluntad es quedarse corto. No digo que no exista la fruición del bien, sino que es imposible sin el amor donal" ${ }_{52}$. En este mismo, cuando explica la elevación del querer al ámbito trascendental humano, afirma que "la misma fruición debe ser susceptible de ser ofrecida. Es claro que la actividad oferente no comporta degradación. Sin esta ampliación no se ve cómo sería posible el acto fruitivo" ${ }^{3}$.

Finalicemos este epígrafe recordando que en los escritos de Polo se cuestiona la fruición como acto voluntario seguido al uso y a la intención. Además, la experiencia vital nos remarca que después del actuar se llega a poseer un bien; de ahí que se propone la posesión como acto seguido a la intención y al uso. En la propuesta poliana plantea explícitamente la necesidad de estudiar la cuestión del último acto de la voluntad cuando afirma que "la versión clásica de la fruición es incompleta" ${ }^{54}$. Para delimitar mejor la propuesta de Polo sobre este tema, podemos usar de base la siguiente cita: "La fruitio podrá ser una correspondencia con el bien, pero no es una correspondencia del dar con el

51 Cfr. Polo, L. (2015b), p. 454.

52 Polo, L. (2015b), p. 491. Cfr. también: p. 77.

53 Polo, L. (2015b), p. 77.

54 Polo, L. (2015b), p. 427-428. 
aceptar" 55 . Con ello da lugar a iniciar la propuesta de continuación desde el estudio del afán efusivo de la persona.

\section{ACTOS DE LA VOLUNTAD REFERIDOS AL FIN QUE SIGUEN A LA INTENCIÓN: UNA RECTIFICACIÓN A PARTIR DEL AFÁN POSESIVO Y EFUSIVO PRESENTES EN EL HOMBRE}

En cuanto al movimiento de la voluntad según la propuesta de Aquino, la intención es seguida de otros actos de la voluntas ut ratio: la elección y el uso. El uso no depende completamente de la intención, sino que también sigue a la elección y al imperio de la razón práctica. Pero tanto la deliberación como la elección están influidas por la intención, pues se delibera y elige en función de la intención ${ }^{56}$.

Polo afirma que la fruición está vinculada a la persona y no solo a la voluntad, cuando afirma que manifiesta la estructura donal de la persona. Si la fruición también es de índole personal y no solo voluntaria, cabe preguntarse ahora cuál es el acto que sigue a la intención en cuanto a los actos voluntarios referidos al fin. Tanto Aquino como Polo reconocen la búsqueda de la posesión de un bien a partir de la intención. Por eso, a partir de lo dicho por Polo se propone considerar la disposición como el acto que sigue al acto de la intención, pero no el último. Para llegar a la disposición -un tipo de posesión abierta a un sentido efusivo del hombre- hacia el bien buscado, esta deberá ser precedida no solo de la intención, sino también de la acción o uso, que, como se dijo, dispone de la inteligencia, la corporeidad y los bienes materiales para alcanzarlo. De acuerdo con el tipo de bien buscado -ya sea material o intelectual- se dispondrá de los bienes mediales anteriormente alcanzados. Este acto de disposición manifiesta la confluencia del afán posesivo presente en el hombre y el afán efusivo radicado en la persona del mismo hombre.

La disposición, como acto voluntario referido al fin seguiría a la intención y sería influido por este acto. Para que la disposición intensifique la iluminación de la sindéresis debe ser ejercida de modo que permita la apertura a los demás. De esta forma, la voluntad seguirá siendo capaz de manifestar el quererquerer-más y no se detendrá en la posesión del bien. Lo que implica que la disposición debe realizarse con respeto a los demás y, de esta forma, queda abierta

55 Polo, L., Conversaciones, pro manuscripto, p. 208. Cfr. también: Polo, L. (2015a), p. 426.

56 Cfr. Polo, L., La conexión de las virtudes, pro manuscripto, p. 15. 
al ejercicio de la justicia, virtud que Polo asocia a la voluntad en cuanto se refiere a los fines.

Si consideráramos la disposición como acto final de la voluntad ut natura, esta propuesta no consideraría el carácter donal de la persona humana y se le debería considerar al hombre más bien posesivo y hasta necesitante. Este hecho nos exige considerar otro acto más que manifieste el carácter donal de persona de forma más intensa y que derivara de lo que Polo llama afán efusivo. Mientras esto no ocurra, la voluntad no manifestará suficientemente la iluminación de la persona mediante la luz propia de la sindéresis, sino que deberíamos aceptar que la voluntad está sujeta a la naturaleza. Con esto, negaríamos la libertad de la voluntad y la deberíamos considerar como determinada ${ }^{57}$.

$\mathrm{El}$ aceptar que la disposición está abierta a querer-querer-más, también implica que este acto no tiene un carácter absoluto, sino es medial respecto un fin más alto; lo cual permite que se constituya en un don ofrecido a otro. Este don debe ser referido a otra persona y se ofrece con la esperanza de ser aceptado. La disposición así entendida también mantiene su naturaleza electiva al decir poseer o no lo generado a partir del uso. También podemos decir que no está en colisión con la naturaleza del querer-yo de la sindéresis, que al ser repercutido por los trascendentales personales es un poseer libre, pero no ostenta un carácter necesitante. Además, buscará disponer de aquellos bienes que manifiestan quién es y posee de forma potencialmente amorosa sin cerrarse en los bienes parciales, sino abierto a otros superiores ${ }^{58}$.

Con este preámbulo, se propondrá ahora el último acto de la voluntad referida al fin. Como se ha mencionado, la voluntad no depende solo de la inteligencia para activarse sino sobre todo de la sindéresis, que la constituye en acto y la acompaña en sus actos y hábitos adquiridos. Si la sindéresis manifiesta el carácter personal, manifestará en cierto grado su donalidad, irrepetibilidad y libertad. De ahí que estos mismos matices deberán constituirse en la voluntad y sus actos. Para hacer la propuesta debemos considerar algunos aspectos relacionados con el amor humano. Este es una manifestación del aceptar y dar personales y se advierte en el ofrecimiento de dones. Estos dones serán fruto de la apertura a los demás y de acciones buenas, por lo que deberán manifestar la intentio finis del acto de la intención. Esta propuesta sigue lo dicho por Polo cuando afirma que "el amor o es personal o no es amor donal" 59 .

57 Cfr. Polo, L. (2015d), p. 313.

58 Cfr. Polo, L. (2015a), p. 492. Asimismo pp. 485-486.

59 Polo, L. (2018a), p. 293. 
Polo también indica que la fruición es parte del amor, por lo que no será suficientemente felicitaria la posesión del bien al no tener en cuenta a la donalidad personal. Ante la llamada a la apertura a los demás y a la manifestación del amor personal, se propone la asignación como último acto voluntario referido al fin. Si la manera de disponer de un bien debe manifestar la iluminación personal en la sindéresis, lo tenido debe estar abierto a ser ofrecido a otros libremente y a manifestar quién se es. También debe dar lugar al crecimiento de las virtudes de la amistad, la justicia, la prudencia, la fortaleza y la templanza. Esta apertura se refiere tanto a bienes materiales como inmateriales, tales como las posesiones intelectuales ${ }^{60}$.

La asignación mantiene la intención de alteridad de la voluntad porque la asignación se constituye en cuanto el don se ofrece a otro. Este don debe ser referido preferiblemente a otra persona, pues se ofrece con la esperanza de ser aceptado. Asimismo, la asignación mantiene su naturaleza electiva al poder dar o no lo ya disponible. También podemos señalar que la asignación responde al querer-yo de la sindéresis, que al ser repercutido por los trascendentales personales, dona libremente, según quién se es y donalmente. Podemos decir que la asignación permite la adecuada contextualización de los medios y la corrección de la acción.

Habiendo concluido la propuesta de los actos voluntarios dirigidos al fin, cabe todavía una última rectificación en el esquema planteado por Tomás de Aquino y seguido por Polo: se propone considerar la elección o decisión como parte de los actos de la voluntas ut natura y no de la voluntas ut ratio. Esta rectificación no es sugerida directamente por Polo, pero encuentra su fundamento en tres aspectos: la naturaleza misma del acto de elección; la conveniencia de la confluencia de la corrección de la razón práctica, la sinceridad del acto voluntario en la voluntas ut ratio y la contextualización de los fines y medios de la voluntas ut natura; el tercer aspecto es de naturaleza metódica, para hacerlo más ajustado a la estructura secuencial utilizada por Tomás de Aquino en los otros actos de la voluntad.

Se iniciará con la justificación en cuanto al método. En la propuesta de Tomás de Aquino y seguida por Polo se puede observar una secuencia en la interacción reconocida entre la razón práctica, la voluntas ut ratio y la voluntas ut natura. La secuencia observada es la siguiente: la razón práctica realiza un acto inicial, el cual da lugar a la continuación en la voluntas ut ratio y este a

60 Cfr. Polo, L. (2015a), p. 487. 
otro acto de la voluntas ut natura. Así pues, el consejo de la razón práctica da lugar al consentimiento de la voluntas ut ratio y este a la intención de la voluntas ut natura. Esta secuencia de interacciones entre la razón práctica, la voluntas ut ratio y la voluntas ut natura vuelve a suceder con los actos de imperio, uso y fruición.

En cambio, en la secuencia de deliberación y elección se rompe esta secuencia en dos maneras: la primera ruptura la constituye la reducción a dos actos en vez de tres, como en los casos anteriores, porque no participa la voluntas ut natura sino solo la razón práctica y la voluntas ut ratio. En el esquema de Aquino y Polo la deliberación de la razón práctica pasa a la elección de la voluntas ut ratio, pero ya no se continúa con un acto de la voluntas ut natura, sino que continúa con el imperio, un acto de la razón práctica. Con ello rompe el método presente en el resto de los actos voluntarios y de la razón práctica.

El segundo aspecto, por el cual se propone esta rectificación, es para favorecer la iluminación de la actuación en cada una de las secuencias de actos razón práctica-voluntas ut ratio-voluntas ut natura, pues en esta secuencia se favorece la corrección de la acción (en la razón práctica), la sinceridad del acto voluntario (en la voluntas ut ratio) y la contextualización de los medios (en la voluntas ut natura) respectivamente. Para fundamentarlo se analizará lo dicho por Polo acerca de los actos de consejo, consentimiento e intención.

Polo propone una rectificación al esquema de Aquino acerca de la naturaleza del acto del consentimiento. Para Aquino el consentimiento se entiende como el asentimiento de la voluntad a los medios considerados por la deliberación o, dicho con mayor exactitud, por el consejo de la razón práctica. En cambio, en la propuesta poliana el consentimiento asiente a la bondad de la pluralidad de bienes concebidos por la inteligencia. El consentimiento es un acto de la voluntad que sigue al acto racional del consejo: consiente la voluntad y asiente la inteligencia. La conexión entre el consejo de la razón práctica y el consentimiento de la voluntad continúan en la decisión. En esto radica el segundo aspecto señalado, si con el consentimiento ya se emitió un juicio sobre los bienes, la decisión debe ser la que realice el juicio acerca de los medios, pues no tendría sentido volver a asentir sobre los fines ${ }^{61}$.

Además, analizar el fundamento del orden de los actos planteado por Polo en lo referido al consejo y el consentimiento también puede arrojar luz

61 Cfr. Polo, L. La conexión de las virtudes, pro manuscripto, p. 4-7. Asimismo Cfr. Polo, L. (2015a), pp. 442-443. Polo, L. (2019), p. 222. Sellés, J. F. (1999), p. 98. 
a la rectificación propuesta acerca de la elección. Que la razón práctica ejerza el consejo y proponga al consentimiento de la voluntas ut ratio un bien permite la sinceridad del acto voluntario. Esta se refiere a la completa exclusión de la astucia al considerar tanto los bienes tal como son, sin desfigurarlos según la conveniencia o factibilidad de quien está actuando. Este cambio también potencializa la consideración de los bienes como parte de un plexo - es decir, los bienes se insertan en un plexo medial y no son aislados como sostiene la filosofía tradicional-. Los bienes al alcance de quien elige forman parte de un plexo y están también disponibles a otros. De ahí que no asentir a los bienes mediales elegibles por los demás atenta contra todo el plexo y, con ello, contra la comunidad social de la cual forma parte; elegir de esta manera implica un error de la razón práctica que debe corregirse ${ }^{62}$.

Otra razón para proponer esta rectificación es el reconocimiento de Polo acerca del modo de ejercer la intención con corrección; para ello es necesario que se considere el juego de medios. Estos medios están organizados según las relaciones existentes entre ellos de forma horizontal, es decir, referidos a medios del mismo nivel jerárquico-ontológico; dicha organización mantiene la relación de los medios con el fin superior que se busque. También indica que la intención posee un doble sentido: uno en referencia al fin y el otro en referencia a la relación de los medios entre sí. Pero si la intención se refiere a los bienes, es necesario otro acto referido a los medios que se vincule a la voluntas ut natura, es decir, la vinculación del medio al fin. Se propone que sea la elección dicho acto ${ }^{63}$.

El tercer aspecto se refiere al acto mismo de la elección, basándose en lo que Polo dice de este acto voluntario. La elección es un acto de la voluntad que sigue al consenso, como ya se ha señalado; esta se refiere a los medios requeridos para lograr los fines previamente establecidos; también sigue a la deliberación en cuanto a los actos de la inteligencia. Así mismo, la elección también mantiene indirectamente una relación con el bien buscado; esta relación se mantiene a través de los actos voluntarios referidos al fin $-\mathrm{y}$ especialmente con la intención-. La elección consiste en el ejercicio de la capacidad de decidirse por uno de los medios en los que ha deliberado la inteligencia, con el fin de alcanzar lo elegido en la intención. Previo a elegir ocurre la aceptación de los bienes que le son presentados por la inteligencia -el consenso-; luego la vo-

62 Cfr. Polo L. (2015a), p. 443.

63 Cfr. Polo L. (2015a), p. 433. 
luntad procede a elegir los medios, pero no lo hace aisladamente, sino en orden al uso. Por lo tanto, se refiere a los medios identificados por la razón y disponibles en ese momento. Si la elección no se refiriera a los medios disponibles, esta no llegaría a la acción y, en ese caso, carecería de sentido lo actuado hasta ese momento ${ }^{64}$.

La elección o decisión es un acto natural al hombre, porque este busca fines concretos, particulares. Esta particularización del bien buscado constituye una diferencia radical con la inteligencia, que se contenta con lo general, lo especulativo, lo universal. Para poder alcanzar ese fin, el hombre tiene que actuar y, para hacerlo, previamente tiene que decidir. Durante la decisión, proyecta la utilización de los medios requeridos y disponibles para alcanzar el fin establecido; como los medios tienen su propio modo de ser y forman parte de un plexo, estos no pueden considerarse potencia del acto voluntario, sino que debe respetarse su propia manera de ser de medios. Esta distinción evita el uso indiscriminado de los medios en la consecución de un fin o, dicho de otra manera, el fin no justifica los medios ${ }^{65}$.

La filosofía clásica considera que el libre albedrío es una propiedad de la voluntas ut ratio y pertenece al acto voluntario de la elección. Según esto, la voluntad puede elegir dentro de los medios que le son ofrecidos por la deliberación y esta indeterminación permite elegir entre lo ofrecido por la razón práctica. Aunque existe una conexión entre la razón y la voluntad en la elección, la distinción entre la deliberación y la elección -el primero siendo un acto de la inteligencia y el otro, de la voluntad-, evita el riesgo de reducir la decisión al cálculo de probabilidades -método muchas veces utilizado para construir un árbol de decisiones-, por dar un ejemplo. Si no se distinguen suficientemente la deliberación de la elección, también puede acontecer una desconexión con el plexo medial. Esto podría reducir el grado de sociabilidad que permite la consideración desde la voluntad a los medios ofrecidos por la inteligencia. Además, reconoce la importancia de la voluntad en el proceso de decisión, y al mismo tiempo que se cuenta con el apoyo indispensable de la inteligencia nos aleja del intelectualismo. Esta postura reconoce que la libertad del libre albedrío no depende sólo del intelecto, aunque sí esté influida por este $^{66}$.

64 Cfr. Polo, L. (2015f), pp. 69-71, 89. Polo, L. (2015a), p. 443, p. 445, p. 448.

65 Polo, L. (2015f), pp. 70-71.

66 Cfr Polo, L. (2015f), p. 67, p. 112. Asimismo, Polo, L. (2015a), pp. 445-446. 
El libre albedrío se extiende a la voluntad solo en cuanto ésta posea virtudes, de ahí la sentencia de que las virtudes nos hacen ser más libres. Esta capacidad de modificar la tendencia es posible porque la virtud se abre a un bien más alto: el bien trascendente. Este fin es de suyo más alto que los que pueda presentarme la inteligencia y solo se puede tender a él por la iluminación que ejerce la sindéresis en la voluntad; la cual, a su vez, es activada por el amor de la persona. Si la elección manifiesta el amor, no podría referirse a medios sino a fines, por lo que es mejor considerarla como acto de la voluntas ut natura ${ }^{67}$.

Como se puede observar, la elección está muy vinculada a los fines, pero esa vinculación es distinta a la ejercida desde la intención; la elección intensifica la acción de la sindéresis en cuanto permite que la intención se realice, se lleve a cabo por parte del hombre. Además, la elección se encaminaría a la disposición -acto voluntario propuesto anteriormente-. Si la elección se ejerce de forma adecuada, fortalece las virtudes propias de la voluntas ut natura: la amistad y la justicia. Para completar la propuesta se sugiere considerar el juicio práctico como el acto voluntario de la voluntas ut ratio que precede a la elección. Sería en este acto donde se cumple la sinceridad del acto voluntario y se propone a la voluntas ut ratio para su acción judicativa. En cuanto al método usado por Tomás de Aquino y Polo, se seguía contando con la secuencia de acto de la razón práctica, acto de la voluntas ut ratio y ratificado por un acto de la voluntas ut natura. Estos serían la deliberación, el juicio práctico y la elección.

Polo cuando se refiere al juicio práctico señala claramente su vinculación con el plexo de los medios y la intención. Pero no solo la intención propia sino relacionada con la vinculación de las intenciones de otros. Diferencia el acto del juicio práctico de la elección, pero lo equipara con la deliberación; ante esto cabe señalar que la razón práctica no juzga sino conoce ${ }^{68}$.

La propuesta concreta será considerar como actos voluntarios dirigidos al fin el simple querer, la intención, la elección, la disposición y la asignación. Antes de pasar a la vinculación de estos actos voluntarios referidos al fin y la acción directiva dentro de la empresa, se presentará una propuesta de solución a la fruición, pues constituye parte del esquema desarrollado por Tomás de Aquino. Además, tiene mucho que ver con la actividad empresarial, como se podrá ver luego.

67 Cfr. Polo, L. (2015a), p. p. 446.

68 Cfr. Polo, L. (2015a), pp. 441-442, p. 444, p. 446. 


\section{LA FRUICIÓN COMO UN AFECTO PERSONAL GENERADO A PARTIR DE LA ACEPTACIÓN LIBRE DEL ORIGEN Y EL DESTINO PERSONAL}

Hasta este punto se han propuesto dos actos voluntarios referidos al fin que parecen manifestar de forma más adecuada a la persona humana y su manera de actuar, apoyados en la antropología trascendental. Sin embargo, no se ha concluido sobre la fruición. Iniciemos este apartado diciendo que la fruición es una realidad vital en el hombre: uno goza o se deleita en la vida y que a juicio de Polo la propuesta del Aquilate debe ser revisada. También aclara que la fruición es de índole personal; por eso mismo, está abierta otros. La donalidad y la apertura a otros son aspectos que quedan imposibilitados según la propuesta clásica por manifestar únicamente el afán posesivo del hombre ${ }^{69}$.

Es asimismo importante considerar que el primer acto del amor personal es la aceptación, que lleva a la donación y esta se manifiesta en el don; por su parte, el don ofrecido debe ser aceptado para que el amor sea real. A partir de esta realidad personal, se propone que la fruición posee un origen dual: de la aceptación personal de sí mismo de quien actúa: del don del ser recibido en cuanto un ser personal. Su segunda fuente, la aceptación de lo ofrecido a otra persona. Por eso, Polo consideraba la fruición como un acto personal y no voluntario ${ }^{70}$.

En cuanto reconoce que la fruición completa se dará solo con la posesión del fin trascendental -que no se da en este mundo- sigue la propuesta clásica, pero se separa de ella al afirmar que no depende de la posesión del bien sino en el ejercicio de la estructura donal. Si esto no fuera así, la incapacidad intelectual de acceder al bien trascendental impediría la fruición en la voluntad. Ante este hecho, Aquino apostilla que en este mundo no es posible la felicidad completa. Pero esto abre a una disyuntiva: de qué manera podríamos hablar de fruición si no es posible experimentarlo y por lo tanto habría que declararlo imposible; o existe otra manera de fundamentarlo ${ }^{71}$.

Un aspecto que cabe apuntar es el hecho de que la fruición y la acción están asociadas; pero la experiencia vital nos muestra que no todas las acciones la generan y, aquellas que la generan, no lo hacen en el mismo grado. En esto coinciden tanto Polo como Aquino. Ante la posibilidad de actuar y no gozar de

69 Cfr. Polo, L. (2015a), p. 370.

70 Cfr. Polo, L. (2015a), p. 251.

71 Cfr. Polo, L. (2015a), p. 426. 
la fruición, es importante considerar las razones que generan o impiden una fruición en el hombre. También debe considerarse si la fruición, al igual que las realidades esenciales y personales en el hombre, permite un crecimiento irrestricto o será limitado. Por último, sería conveniente reflexionar si la fruición es un acto o un afecto. Iniciaremos con el último de los aspectos.

Si la experiencia vital y las propuestas de Aquino y Polo consideran que la fruición se deriva de la acción realizada, está no debe constituir un acto sino un afecto. La fruición sería un afecto personal, pues su índole lo es. Ahora bien, Polo también reconoce que la fruición se puede dar en cierta medida en las dimensiones esenciales y corpóreas del hombre, pero la fruición debería ser mayor cuanto más elevada sea la dimensión a partir de la cual se deriva: la fruición más alta sería la personal que se podría denominar gozo; seguida de la generada a partir de los hábitos innatos, que se podría llamar sabrosura, tranquilidad y suavidad, para la sabiduría, primeros principios y sindéresis, respectivamente; la de la esencia humana sería la fruición; la del cuerpo el placer.

Se ha mencionado que la persona repercute en las dimensiones inferiores a través de su libertad; esta repercusión debería manifestar los dos ámbitos de la libertad: la de origen y la destinación. La libertad de origen permite al hombre aceptarse como ser creado y, por lo tanto, sujeto a disponer según un modo de ser que le es dado. Por esto, en la medida en que el actuar manifieste según su verdad, manifestará la aceptación del don recibido: ser capaz de conocerse por el hábito de la sabiduría, capaz de conocer la realidad extramental por el hábito de los primeros principios y capaz de armonizar su actuar mediante el hábito de la sindéresis. También manifestará ese aceptar del don recibido cuando ejerza la acción según la verdad constitutiva de las potencias esenciales: según la intención de semejanza de la inteligencia y la de alteridad de la voluntad. Por último, manifestará el poseer humano como manifestativo de su corporeidad.

En la medida en que ejerza su acción según las distintas dimensiones humanas según la verdad en cada una de sus dimensiones, será capaz de gozar de un grado más alto de la fruición. Esta propuesta coincide con la clásica de considerar que en esta vida no se alcanza la fruición más alta, pero pareciera ser más esperanzada y optimista -característica que resalta en la antropología poliana-.

La libertad de origen llevará a la aceptación de ser creatura, como fruto de una donación amorosa de parte de Alguien -Dios- y con la contribución de sus padres. Sin embargo, si no ejerciera su actuar según la libertad de destina- 
ción, su fruición sería incompleta y cerrada al aspecto más alto de este trascendental personal. Por lo tanto, es importante considerar que el actuar humano libre debe ser encaminado a conocer quién soy y, sobre todo, al amor de correspondencia a su Creador.

Ahora abordemos el segundo aspecto planteado: la capacidad de crecimiento de la fruición. Según la propuesta poliana, la persona, sus hábitos innatos y su esencia permiten un crecimiento irrestricto; en el caso de la naturaleza corpórea, en cambio, es limitada. Si consideramos con Polo que la fruición es de índole donal y, por lo tanto, refleja a la personal deberíamos aceptar que dicho afecto también permite un crecimiento irrestricto, capacidad que no mengua al morir, sino que es posible acrecentar. Como es personal, debe estar ordenada al amor -que exige estar abierta a aceptar por otro y el ofrecimiento de dones- ${ }^{72}$.

Como la finalidad del hombre es amar, será la donación la que manifieste esa llamada personal y, por lo tanto, será la que mayor fruición genere al manifestar mejor su doble vertiente antes señalada: la aceptación de sí mismo como don recibido de Dios y la apertura a ofrecer dones a otras personas, tanto la divina como las humanas. Este acto es puramente alterativo y responde a las objeciones planteadas por Polo acerca de la propuesta clásica sobre la fruición ${ }^{73}$.

En la medida en que la aceptación sea mayor, más grande será también la fruición. En cuanto a la primera dualidad de la fruición -la aceptación personal de sí mismo-, si una persona solo se queda en la dimensión material, su fruición será de menor intensidad que si se refiere también a la dimensión corporal; pero si sigue ascendiendo además a lo esencial, su fruición será todavía más grande; pero si además trasciende lo esencial y alcanza también lo personal, su fruición se incrementará. Por último, puede ser mayor si se refiere a Dios y, por Él, a los demás. Este último grado será pleno en la posesión definitiva del Bien Supremo, que se dará después de esta vida; pero en esta vida, el ofrecer los dones a Dios y por Él a los demás, elimina la posibilidad de destrucción del amor por falta de correspondencia humana ${ }^{74}$.

Es importante notar que la propuesta señala distintos grados, según sea la aceptación de las distintas dimensiones humanas (corporal, esencial y per-

72 Cfr. Polo, L. (2015a), pp. 454-455.

73 Cfr. Polo, L. (2015a), pp. 367-368 y p. 426.

74 Cfr. Polo, L. (2015a), pp. 456-457. 
sonal), pues decantarse únicamente por las superiores con desprecio de las inferiores sería contrariar el modo de ser humano: un ser corporal-esencial-personal. Pero decantarse sólo por las inferiores sería aún peor, pues rebaja a la persona al concebirla únicamente como un ser capaz de poseer, pero incapaz de ofrecer dones.

Si consideramos la acción personal referida a la vertiente destinataria de la libertad, podríamos explicar por qué Polo señala que la amistad y la fruición se corresponden: la fruición ocurre cuando se ofrece una buena acción o un bien y se aumenta cuando se contempla la aceptación de dicha acción por el otro. Al hablar de unión entre personas, se habla de una mutua correspondencia: "amarse como amante precisamente por saberse amado, puesto que sólo así el amor del otro no está obligado a destruirse. Y esto es la culminación de la felicidad. La unión es la mutua aceptación"75.

Ahora bien, si la fruición está abierta al amor, está relacionada con la esperanza -pues el amor y la esperanza están relacionados-. El amor humano es un amor esperanzado: mira a la correspondencia, a una aceptación. Pero nuestra experiencia es que aun un amor humano no sacia completamente, se busca una aceptación más donal que el amor humano: un querer-querer-más. La fruición solo es posible si la persona está abierta esperanzadamente al bien trascendental -a Dios-. El amor humano, siguiendo su orden, también debe estar ordenado a Dios: es Él quien otorga y sostiene el sentido del amor y permite la fruición en la voluntad mediante la posesión esperanzada del bien y no por una posesión física o intelectual de este ${ }^{76}$.

\section{CONCLUSIONES Y PROPUESTA DE FUNDAMENTACIÓN ANTROPOLÓGICA DE LA GESTIÓN DIRECTIVA DE LA EMPRESA}

En el hombre confluyen los afanes posesivos y efusivos porque son constitutivos de la persona humana. El primero corresponde a la verdad de la corporeidad y la esencia humana; el segundo, a la redundancia de la persona. Por eso, el afán efusivo es de jerarquía más alta que el posesivo; no lo anula sino lo ordena y eleva.

La propuesta de actos voluntarios referidos al fin elaborada por Tomás de Aquino es un gran aporte a la filosofía. Sin embargo, al iluminar esta pro-

75 Polo, L. (2015a), p. 493.

76 Cfr. Polo, L. (2015b), pp. 427-428. 
puesta desde la distinción entre la esencia y el acto de ser -descubierta por Aquino y remarcada de manera especial por Polo-, puede ser continuada para que refleje mejor la verdad de constitución de la voluntad a partir de la dimensión del querer-yo de la sindéresis. El querer-yo llevará a la voluntad a crecer en el querer-querer-más, que se refiere a mejorar la tendencialidad voluntaria y convertirla en una orientación de carácter destinal.

La voluntad debe reflejar ser personalizada o verdadeada desde el amor personal. Por lo tanto, es importante continuar la propuesta de Aquino con un acto voluntario referido al fin que sea de naturaleza donal. En este sentido, la asignación como fin último de la voluntad referida al fin responde mejor a la constitución de la voluntad. Para que la asignación sea posible se requiere previamente ejercer la disposición.

Los actos voluntarios dirigidos al fin pueden constituir un fundamento antropológico para la acción directiva en la actualidad: el simple querer se identifica con la determinación del propósito que busca el empresario; la intención con el establecimiento de los objetivos; la elección con la determinación de la estrategia a seguir; la disposición con la obtención del beneficio abierto al bien propio y común -no adscrito de forma absoluta- y la asignación con la distribución de los beneficios -incluyendo las utilidades y los sueldos como propone Polo-. Con esta propuesta el empresario encontraría un modo para hacer confluir los afanes posesivos y efusivos presentes en todo hombre.

En el caso de la empresa los actos voluntarios también pudieran servir de base para el establecimiento del propósito y la manera de llevarlo a cabo en la práctica. En este caso el simple querer seguiría siendo el propósito pero visto ya no individualmente sino de forma compartida; la intención se identificaría con la propuesta de valor de la empresa; la elección con la estrategia de la institución; la disposición con la obtención de los beneficios económicos; y la asignación determinará la política de distribución de dichos beneficios que incluiría a los accionistas, trabajadores y sociedad -a través de los impuestos o asignaciones que voluntariamente se establecieran dentro de la empresa. Utilizar de base los actos de la voluntad dirigidos al fin, permite establecer una base de confluencia de los afanes posesivos y efusivos tanto en lo económico como en la prestación de un servicio a la sociedad. Con esto podremos ofre-

77 Polo, L. (2015b), p. 416. 
cer una guía para hacer valer la propuesta de Polo acerca de la empresa: "ni servicio sin beneficio, ni beneficio sin servicio" 77 .

\section{BIBLIOGRAFÍA}

Corazón, Rafael (2003), "Sobre la esencia humana", Studia Poliana, n 6 , pp. 211-223.

Ferrer, Urbano (2010), “Temporalidad y esencia del hombre”, Studia Poliana, $\mathrm{n}^{\mathrm{o}} 12$, pp. 105-116.

Gallego, José Andrés; Fernández, Fernando y Gómez, R. (2019), en la presentación de García González, Juan A. (2019), El hombre como persona, Ideas y libros ediciones, Madrid.

García, Juan A. (2011), "La libertad trascendental y la persona humana”, Studia Poliana, n 13, pp. 51-67.

Polo, Leonardo (2011), "Las tres dimensiones de la antropología", Studia Poliana, $\mathrm{n}^{\circ} 13$, pp. 15-29.

Polo, Leonardo (2013), Lecciones de ética, EUNSA, Pamplona.

Polo, Leonardo (2015), Antropología trascendental, en Obras Completas, Serie A, vol. XV, Pamplona, Eunsa.

Polo, Leonardo (2015), Filosofía y economía, en Obras Completas, Serie A, vol. XXV, Pamplona, Eunsa.

Polo, Leonardo (2015), Introducción a la filosofía, en Obras completas, Serie A, vol. XII, Pamplona, Eunsa.

Polo, Leonardo (2015), La esencia del hombre, en Obras completas, Serie A, vol. XXIII, Pamplona, Eunsa.

Polo, Leonardo (2015), La persona bumana y su crecimiento, en Obras completas, Serie A, vol. XIII, Pamplona, Eunsa.

Polo, Leonardo (2015), Lecciones de psicología clásica, en Obras Completas, Serie A, vol. XXII, Pamplona, Eunsa.

Polo, Leonardo (2017), Persona y libertad, en Obras completas, Serie A, vol. XIX, Pamplona, Eunsa.

Polo, Leonardo (2018), Escritos menores 2001-2014, en Obras Completas, Serie A, vol. XXVI, Pamplona, Eunsa. 
Polo, Leonardo (2018), Ética. Hacia una versión moderno de los temas clásicos en Obras completas, Serie A, vol. XI, Pamplona, Eunsa.

Polo, Leonardo (2019), Ayudar a crecer, en Obras completas, Serie A, vol. XVIII, Pamplona, Eunsa.

Polo, Leonardo Conversaciones, pro manuscripto.

Polo, Leonardo La conexión de las virtudes, pro manuscripto.

Polo, Leonardo La sociedad, pro manuscripto.

Polo, Leonardo, Filosofía política, pro manuscripto.

Rodríguez Sedano, Alfredo (2001), "Coexistencia e intersubjetividad", Studia Poliana, n 3, pp. 9-33.

Rodríguez Sedano, Alfredo y Aguilera, Juan Carlos (2011), "La intersubjetividad a la luz de la apertura íntima personal", Studia Poliana, no 13, pp. 31-49.

Sellés, Juan Fernando (1999), "La prudencia según Tomás de Aquino", Cuadernos de Anuario Filosófico, Serie Universitaria, nº 90.

Sellés, Juan Fernando (2013), "Nueve puntos centrales del directivo", en Familia, Universidad y Empresa, los tres agentes de cambio de la Sociedad, Eiunsa, Pamplona.

Urabayen, Julia (2003), "Estudio del "tener" según Gabriel Marcel y Leonardo Polo", Studia Poliana, n 5, pp. 199-239.

Yepes, Ricardo (1997), La persona y su intimidad, Pamplona, Serie Universitaria, $n^{\circ} 48$. 
